\title{
Octreotide treatment of cancer chemoradiotherapy-induced diarrhoea: a meta-analysis of randomized controlled trials
}

\author{
De-Jian Ma ${ }^{1,2}$, Zeng-Jun $\mathrm{Li}^{2}$, Xi-Yan Wang ${ }^{3}$, Xian-Jun Zhu ${ }^{4}$, Yan-Lai Sun ${ }^{2}$ \\ ${ }^{1}$ School of Medicine and Life Sciences, University of Jinan-Shandong Academy of Medical Sciences, Jinan 250062, China; ${ }^{2}$ Department of \\ Gastrointestinal Cancer Surgery, Shandong Cancer Hospital and Institute, Shandong First Medical University and Shandong Academy of Medical \\ Sciences, Jinan 250117, China; ${ }^{3}$ Department of Anesthesia, ${ }^{4}$ Department of Radiation, The People's Hospital of Zhangqiu, Jinan 250200 , China \\ Contributions: (I) Conception and design: YL Sun, ZJ Li; (II) Administrative support: YL Sun, ZJ Li; (III) Provision of study materials or patients: XY \\ Wang, DJ Ma; (IV) Collection and assembly of data: XY Wang, XJ Zhu; (V) Data analysis and interpretation: DJ Ma; (VI) Manuscript writing: All \\ authors; (VII) Final approval of manuscript: All authors. \\ Correspondence to: Yan-Lai Sun, MD, Professor. Department of Gastrointestinal Cancer Surgery, Shandong Cancer Hospital and Institute, Shandong \\ First Medical University and Shandong Academy of Medical Sciences, 440 Jiyan Road, Jinan 250117, China. Email: sunyanlai@126.com.
}

\begin{abstract}
Background: Patients receiving radiotherapy and chemotherapy have a high risk developing to an acute chemoradiotherapy-induced diarrhea (RID). The clinical efficacy of octreotide in controlling chemoradiotherapy-induced diarrhea remains controversial. We performed a meta-analysis of randomized controlled trials (RCTs) to evaluate the efficacy of octreotide for treatment the chemoradiotherapy-induced diarrhoea.

Methods: Relevant RCTs studies assessing the effect of octreotide on clinical outcomes compared with placebo were searched in Cochrane Library, PubMed, EMBASE and Web of Science (up to December 2018). Heterogeneity was assessed with $\mathrm{I}^{2}$, and publication bias was evaluated using sensitive analysis.

Results: Eight trials, a total of 594 participants. We found octreotide was significantly effective compared with the control group $(\mathrm{OR}=3.17 ; 95 \% \mathrm{CI}, 1.28-7.85 ; \mathrm{P}<0.0001)$. The overall effect of octreotide was $62.5 \%$ (220/352), while that of the control group was $49.3 \%(168 / 341)$. We found octreotide group was effective compared with the control group in 24, 48, and $96 \mathrm{~h}(\mathrm{OR}=16.02 ; 95 \% \mathrm{CI}, 3.51-73.15 ; \mathrm{P}=0.0003)$, ( $\mathrm{OR}=4.70 ; 95 \% \mathrm{CI}, 1.65-13.42 ; \mathrm{P}=0.004)$ and ( $\mathrm{OR}=14.49 ; 95 \% \mathrm{CI}, 6.24-33.65 ; \mathrm{P}<0.00001)$.
\end{abstract}

Conclusions: Octreotide is superior to conventional therapy in the duration and effectiveness for chemoradiotherapy-induced diarrhea.

Keywords: Diarrhea; chemoradiotherapy; meta-analysis; octreotide; opioids

Submitted May 27, 2019. Accepted for publication Sep 04, 2019.

doi: $10.21037 /$ tcr.2019.09.49

View this article at: http://dx.doi.org/10.21037/tcr.2019.09.49

\section{Introduction}

Cancers are well-known as leading causes of death. There are more than 14.1 million new cancer cases and 6.2 million cancer patients die of cancers each year $(1,2)$. Chemotherapy and radiotherapy are the main treatments for malignant tumours $(3,4)$. Radiotherapy-induced diarrhoea (RID) or chemotherapy-induced diarrhoea (CID) are common adverse reactions in the course of therapy in cancer patients, especially in treatments containing 5 -fluorouracil (5-FU), irinotecan and capecitabine (5). Diarrhoea not only reduces the patients' physique and quality of life but also leads to the dysregulation of water and electrolytes, decreased blood volume, increased incidence of infection, shock that can be life-threatening, increased cost of hospitalization of patients, or interrupted treatment, which ultimately significantly reduces quality of life. Delays in radiotherapy and chemotherapy, dose reductions interfere with optimal cancer treatment and prognosis (6-9). However, the pathophysiological mechanism of RID or CID is not fully 
understood, but histopathological evidence shows that RID or CID may be a multifactorial process leading to an imbalance in intestinal absorption and secretion $(10,11)$. In spite of the prevalence and severity of RID and CID, they are often not recognized by clinicians and are poorly managed.

Octreotide is a synthetic cyclic octapeptide somatostatin analogue that plays an important role in the treatment of congenital hyperinsulinism, neonates with chylothorax, acromegaly and gastrointestinal neuroendocrine tumours. It can directly act on epithelial cells, inhibit the secretion of gastrointestinal hormones, prolong the passage time of the intestine, and increase the reabsorption of water and electrolytes by the intestinal tube. Compared with the conventional formulation, octreotide has the advantages of slow release, a steady plasma concentration and convenient application (12-25). In particular, the pharmacokinetic profile of octreotide indicates that it may be a good agent to prevent diarrhoea $(26,27)$. Also, hospitalization is often required to replenish fluids and electrolytes during dehydration, which increases the patient's medical costs. The benefits of budesonide, probiotics, antibiotics, activated carbon and traditional Chinese medicines for diarrhoea are uncertain, and future clinical trials are also necessary (28). Thus, a vigilant and more aggressive control for chemoradiotherapy-induced diarrhoea is beneficial to patients with cancer in reducing morbidity and medical expenses.

So far, the preventive and therapeutic effects on chemoradiotherapy-induced diarrhoea have been studied, but the aspects therapeutic effects have not been fully clarified (29). To systematically review the effects of octreotide on the treatment of chemoradiotherapy-induced diarrhoea, we conducted a meta-analysis (30-37).

\section{Methods}

\section{Criteria for considering studies for this review}

\section{Inclusion criteria}

(I) Published randomized and controlled trials (RCTs); (II) studies that included people with a diagnosis of cancer who had received octreotide; (III) studies that included patients who received radiotherapy, chemotherapy or both; (IV) studies without other diseases or influencing factors that can cause diarrhoea; (V) studies that provided the incidence of radiotherapy- or chemotherapy-associated diarrhoea.

\section{Exclusion criteria}

(I) Cohort studies, case-control studies and non-randomized controlled trials; (II) trials on animals; (III) studies with no ending index and unpublished research; (IV) repetitive research.

\section{Interventions}

The interventions were different for different purposes. Treatment of radiotherapy- or CID: patients in the experimental group were given symptomatic treatment with octreotide, and patients in the control group were given only conventional symptomatic treatment. Conventional symptomatic treatment mainly consists of giving opioids, a placebo or rehydration.

\section{Types of outcome measures and requirements}

Major outcomes: (I) the total effective rate of octreotide in preventing and treating diarrhoea caused by chemotherapy or radiotherapy; (II) the effective rate comparison of diarrhoea caused by chemotherapy or radiotherapy in the octreotide treatment and prevention groups; (III) the effective rate comparison of octreotide or opioid treatment of CID or RID; (IV) the effective rate comparison of 24,48 , and $96 \mathrm{~h}$ octreotide groups and the control group.

\section{Efficacy criteria}

According to the National Cancer Institute Common Terminology Criteria for Adverse Events version 4.0 (NCICTCAE4.0), http://evs.nci.nih.gov/ftp1 /CTCAE/CTCAE -4.0 diarrhoea is divided into grades I through $\mathrm{V}$. Among them, Grade I: compared with the baseline, the number of bowel movements increased by $<4$ times/d and the discharge increased slightly; Grade II: the number of bowel movements increased by $4-6$ times/ $\mathrm{d}$ and the discharge increased moderately; Grade III: the number of bowel movements increased by $\geq 7$ times/d and the discharge seriously increased and could be life-threatening; Grade IV: life-threatening, requiring urgent treatment; Grade V: leading to death. Complete response (CR) indicates that the patient's bowel movements returned to normal; partial relief (partial response, PR) indicates a reduction in the severity of the patient's diarrhoea.

\section{Search strategy}

We searched the Cochrane Library, PubMed, EMBASE and Web of Science up to December 2018. We also hand- 


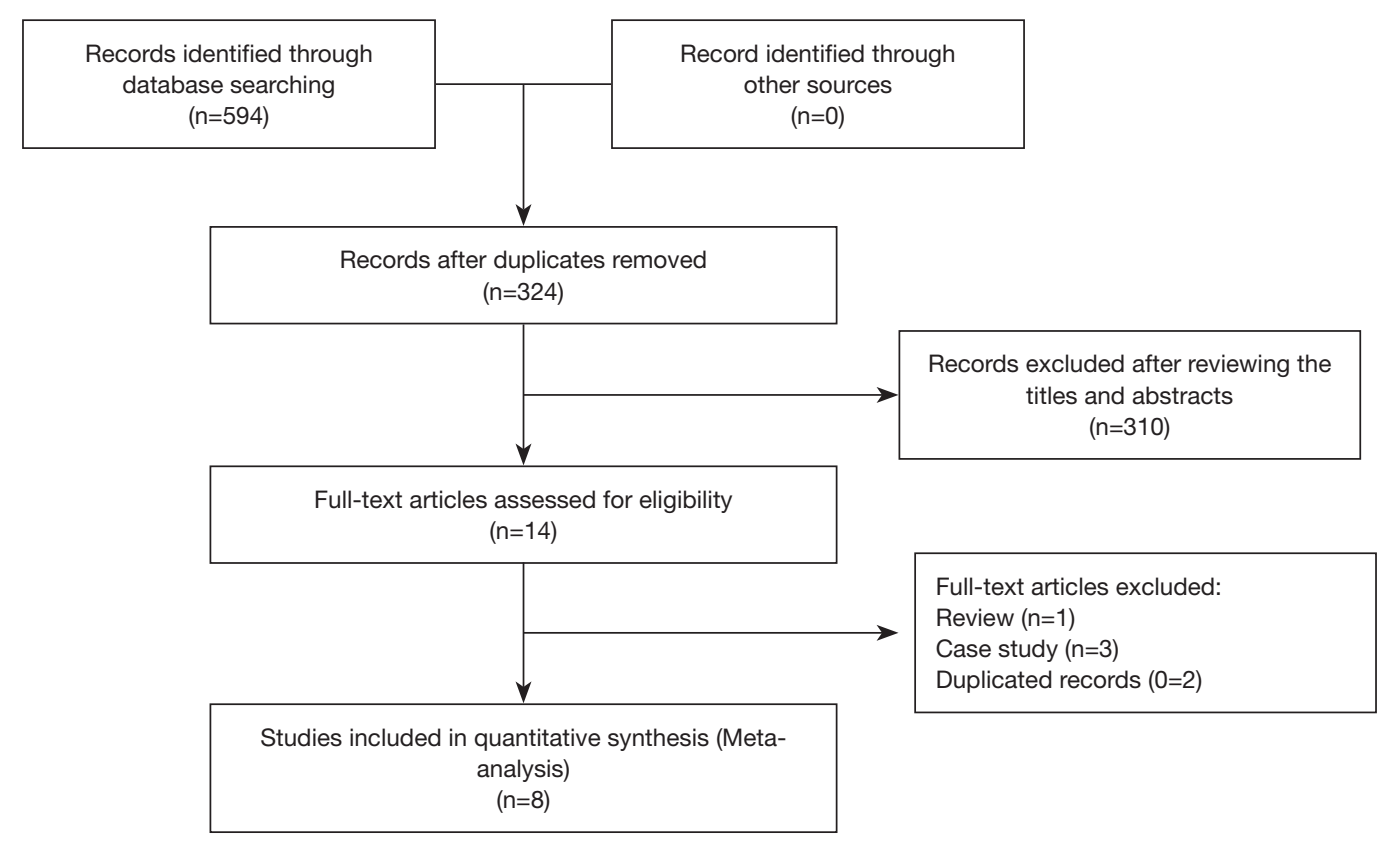

Figure 1 PRISMA flow diagram of the search result of the meta-analysis.

searched the citation lists of included studies and previously identified systematic reviews to identify further relevant trials.

We searched the databases in English, including the references within some literature we read.

\section{Data review and extraction}

Each of the published documents was initially screened by two reviewers according to the inclusion/exclusion criteria, and the articles that clearly did not meet the inclusion criteria were removed by reading the questions and abstracts. Then, the full text of the documents was read to determine whether the inclusion criteria were met. Finally, the final literature screening results were determined by cross-checking by two reviewers. Two researchers used the established data extraction form to extract and check the literature (Figure 1).

The main data extracted included (I) general information (title, author, publication date, and source of literature); (II) basic characteristics of the research design (randomization methods, allocation concealment, blinding, number of cases withdrawn, and explanations); (III) basic characteristics of the subject (case number, age, sex, tumour type and stage, chemotherapy regimen, and diarrhoea grade); (IV) interventions (dosing regimen and course of treatment for the experimental and control groups); (V) efficacy criteria (diarrhoea grading); (VI) outcome measures (total effectiveness of diarrhoea prevention, CR rate, PR rate, treatment failure rate, proportion of patients requiring increased drug dose, incidence of adverse reactions, etc.). Finally, the divergent data were discussed until an agreement was reached.

\section{Quality assessment}

The overall details of risk of bias were shown (Figures 2,3). Papers selected for retrieval were assessed by two independent reviewers for methodological validity prior to inclusion in the review using standardised critical appraisal instruments for RCTs available through The Cochrane Collaboration. Four trials were categorized as being at low risk of bias, one as being at unclear risk of bias and three as being at high risk of bias. All quality measures recorded, and data extracted for meta-analysis, occurred within Review Manager 5.3.

\section{Statistical analysis}

Statistical analysis was performed using the Review Manager 5.3 version of the statistical software to determine the odds ratio $(\mathrm{OR})$ as the effect scale indicator and to 


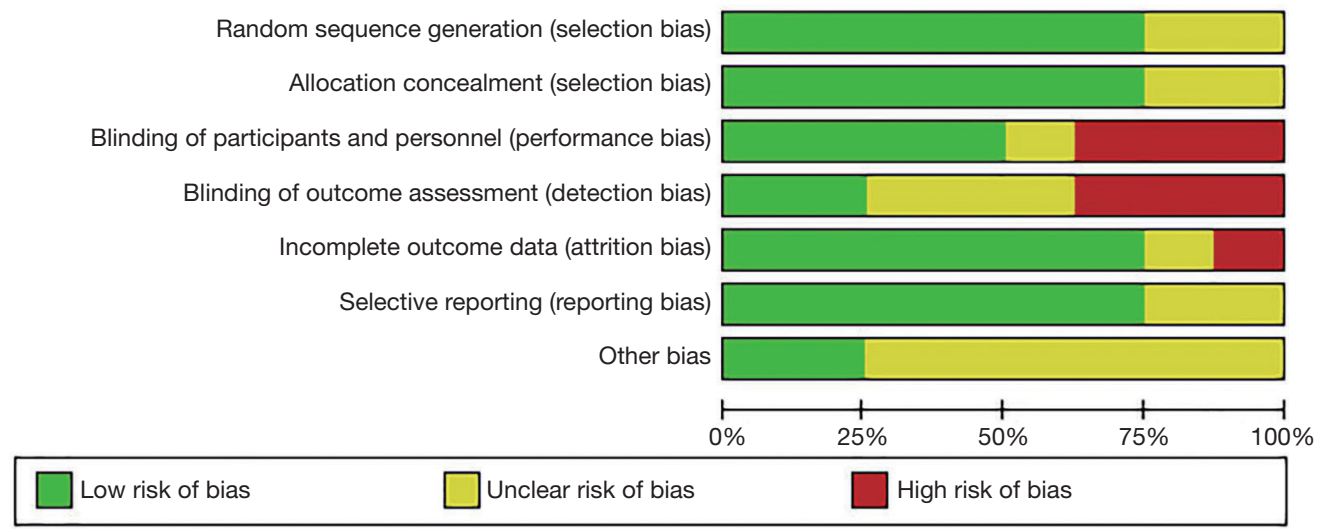

Figure 2 Risk of bias.

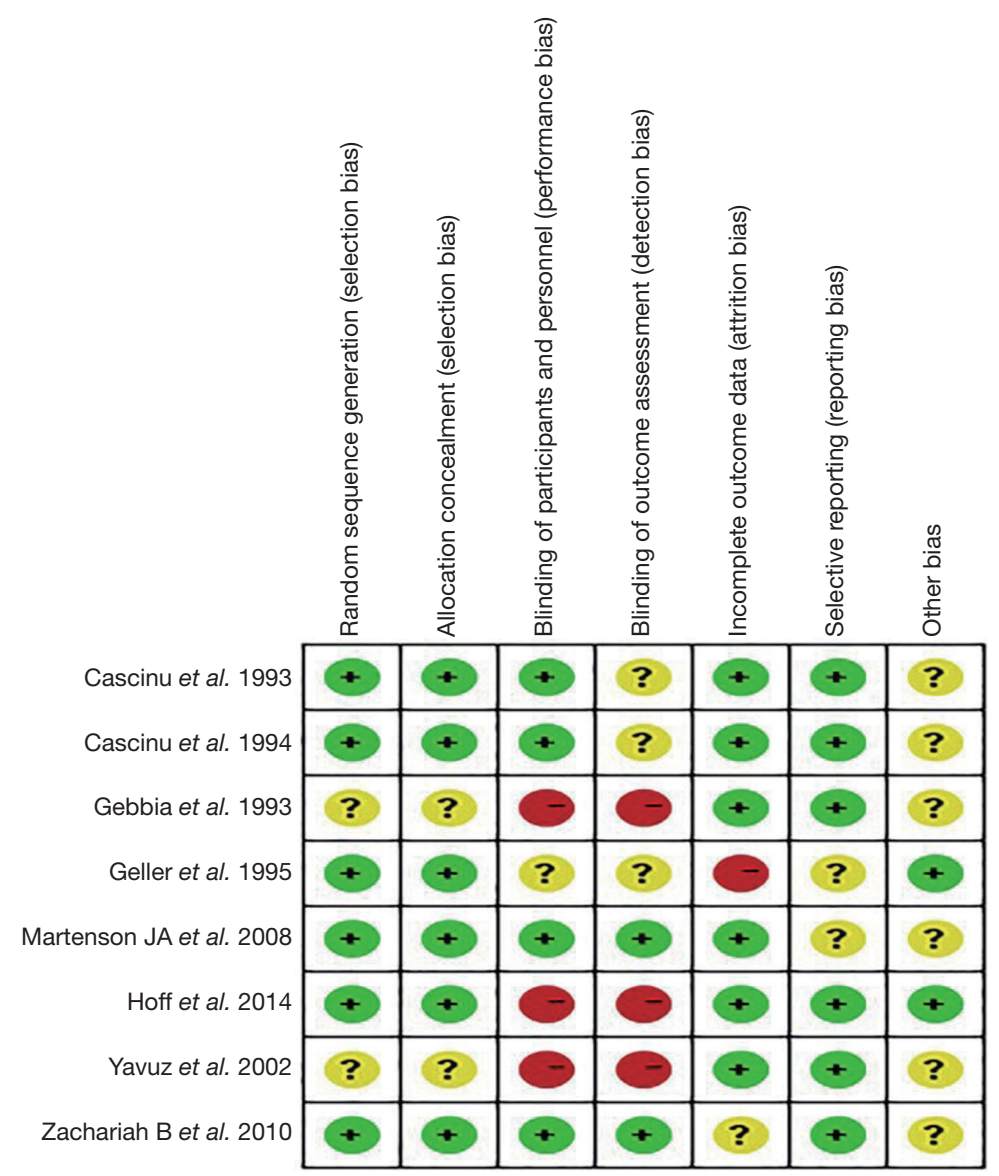

Figure 3 Risk of bias summary.

calculate its $95 \%$ confidence interval (CI), which was considered statistically significant at $\mathrm{P}<0.05$. The Chisquare test was used to detect the presence of heterogeneity, and the degree of heterogeneity was assessed by $\mathrm{I}^{2}: \mathrm{I}^{2}$ values of $25 \%, 50 \%$, and $75 \%$ have been suggested as indicators of low, moderate and high heterogeneity, respectively. If the heterogeneity between the studies was significant $\left(\mathrm{I}^{2}>50 \%\right)$, the random effects model was used for the combined 
Table 1 Characteristics of included studies for the analysis of efficacy

\begin{tabular}{|c|c|c|c|c|c|c|c|c|}
\hline Study & Year & $\begin{array}{l}\text { Tumor } \\
\text { location }\end{array}$ & $\begin{array}{l}\text { Treatment } \\
\text { duration }\end{array}$ & Indication & \multicolumn{2}{|c|}{ Patients (n) } & \multicolumn{2}{|c|}{ Therapy } \\
\hline Gebbia et al. (36) & 1993 & $\begin{array}{l}\text { Various } \\
\text { cancer }\end{array}$ & 4 days & $\begin{array}{l}\text { Chemotherapy } \\
\text { (therapy) }\end{array}$ & 20 & 20 & Octreotide & Loperamide \\
\hline Cascinu et al. (32) & 1993 & $\begin{array}{l}\text { Various } \\
\text { cancer }\end{array}$ & 3 days & $\begin{array}{l}\text { Chemotherapy } \\
\text { (therapy) }\end{array}$ & 21 & 20 & Octreotide & Loperamide \\
\hline Geller et al. (35) & 1995 & Leukemia & 2 days & $\begin{array}{l}\text { Chemotherapy } \\
\text { (therapy) }\end{array}$ & 18 & 13 & Octreotide & Loperamide \\
\hline Yavuz et al. (37) & 2002 & $\begin{array}{l}\text { Various } \\
\text { cancer }\end{array}$ & 3 days & $\begin{array}{l}\text { Radiotherapy } \\
\text { (therapy) }\end{array}$ & 33 & 28 & Octreotide & Diphenoxylate \\
\hline Zachariah et al. (31) & 2010 & $\begin{array}{l}\text { Rectal cancer, } \\
\text { anal cancer }\end{array}$ & 1 month & $\begin{array}{l}\text { Radiotherapy } \\
\text { (prophylaxis) }\end{array}$ & 109 & 106 & $\begin{array}{l}\text { Long-acting } \\
\text { octreotide acetate }\end{array}$ & Placebo \\
\hline Hoff et al. (34) & 2014 & $\begin{array}{l}\text { Colorectal } \\
\text { cancer }\end{array}$ & 1 month & $\begin{array}{l}\text { Chemotherapy } \\
\text { (prophylaxis) }\end{array}$ & 62 & 63 & $\begin{array}{l}\text { Long-acting } \\
\text { octreotide acetate }\end{array}$ & Loperamide \\
\hline
\end{tabular}

analysis. Otherwise, if $\mathrm{I}^{2} \leq 50 \%$, the fixed effect model was used for the combined analysis. Potential publication bias was assessed by sensitivity analysis (38).

\section{Results}

\section{Results of the search}

The basic characteristics of the included trials are summarized in Table 1. The publication year of included studies ranged from 1993 through 2018. A total of 594 related articles were obtained. After reading the questions and abstracts and eliminating duplicate documents, 14 papers were obtained. After reading the full text, 6 papers were excluded and 8 papers were included.

\section{Characteristics and quality of the included studies}

The eight randomized controlled trials included randomized assignments, six of which were assigned by computergenerated random numbers; the rest of the studies did not describe their randomization approach in detail. Six studies used randomized concealment methods to detail the hidden situation of the random allocation schemes. Four studies used a placebo double-blind trial and detailed the number of cases withdrawn and their causes.

\section{Effects of interventions}

Experimental group: 8 studies involved cases where chemoradiotherapy-associated diarrhoea was treated with octreotide. Control group: 3 studies used a placebo as a control for chemoradiotherapy-associated diarrhoea; the other 5 studies were based on opioids.

\section{Outcomes}

The total effective rate of prevention and treatment of diarrhoea by octreotide

Eight studies compared the total effective rate of chemoradiotherapy-associated diarrhoea between the study group and the control group. There was heterogeneity between the studies $\left(\mathrm{P}<0.0001, \mathrm{I}^{2}=79 \%\right)$, and the heterogeneity may be derived from the differences between the research purpose and the results of the study itself, so the random effects model was used for the analysis. The results showed that the total effective rate of the study group was $62.5 \%$ (220/352), and the total effective rate of the control group was $49.3 \%(168 / 341)$. The difference was statistically significant $(\mathrm{OR}=3.17$; $95 \% \mathrm{CI}, 1.28-7.85$; 


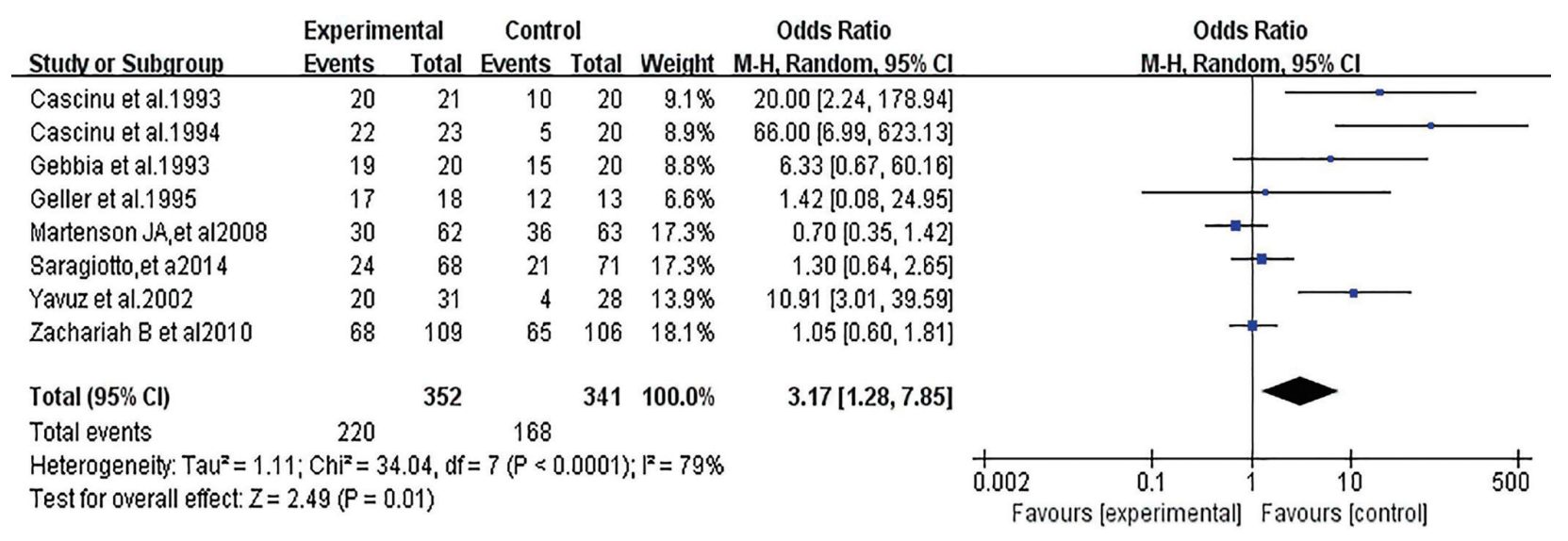

Figure 4 The total effective rate comparison of chemoradiotherapy-associated diarrhoea between the study group and the control group.

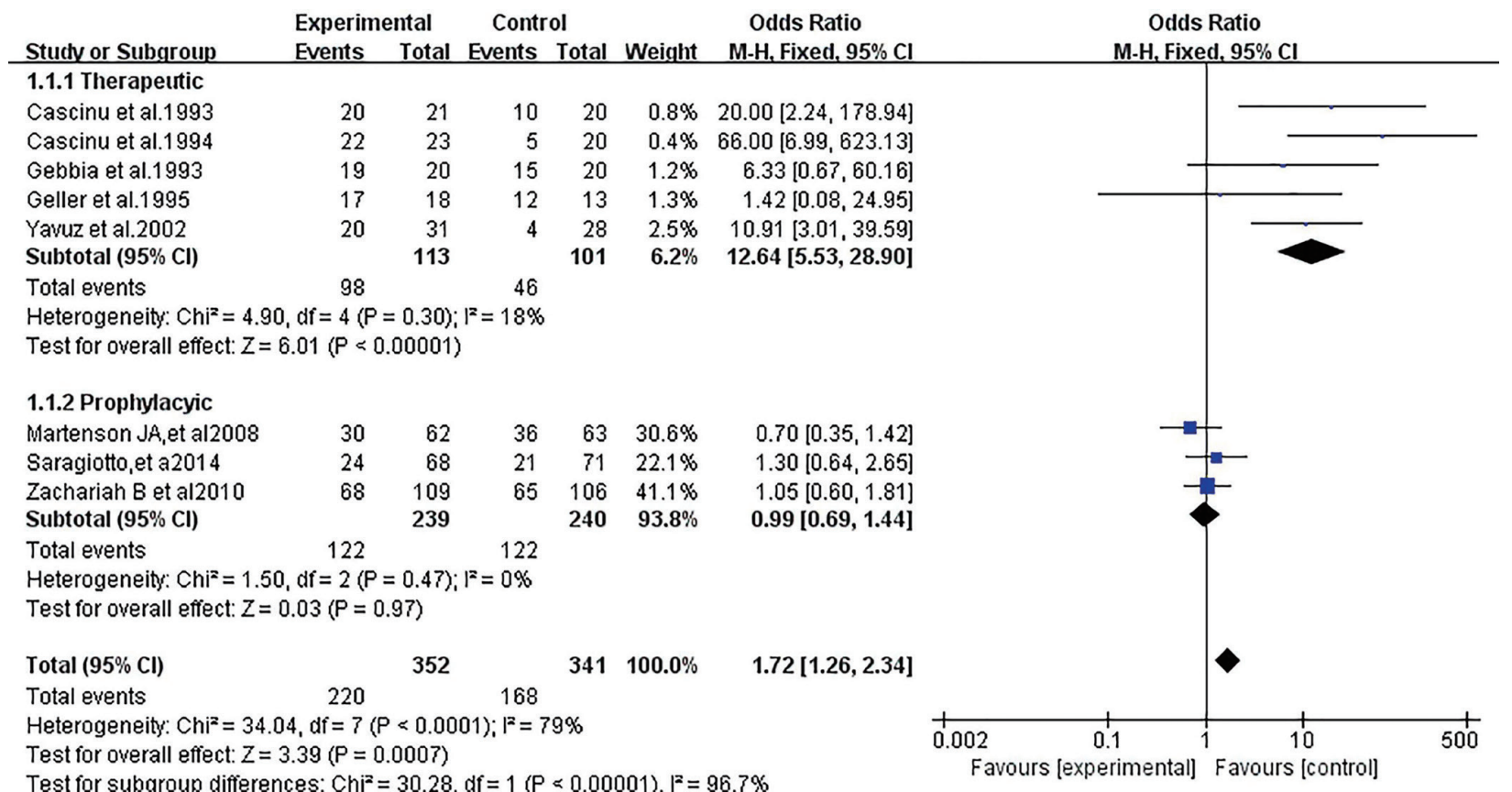

Figure 5 The effective rate comparison of diarrhoea caused by chemotherapy or radiotherapy in the octreotide treatment and prevention groups.

$\mathrm{P}=0.01)$ (Figure 4).

The effective rate comparison of diarrhoea caused by chemotherapy or radiotherapy in the octreotide treatment and prevention groups

In the prevention subgroup, there was no heterogeneity between the studies ( $\left.\mathrm{P}=0.47, \mathrm{I}^{2}=0 \%\right)$, so a fixed effect model was used for the analysis. The total effective rate of diarrhoea prevention in the octreotide treatment group was
$51.0 \%(122 / 239)$, and the total effective rate in the control group was $50.8 \%(122 / 240)$. There was no significant difference between the two groups ( $\mathrm{OR}=0.99 ; 95 \% \mathrm{CI}$, 0.69-1.44; $\mathrm{P}=0.97$ ) (Figure 5).

In the treatment subgroup, there was low heterogeneity between the studies $\left(\mathrm{P}=0.30, \mathrm{I}^{2}=18 \%\right)$, so a fixed effect model was used for the analysis. The total effective rate of octreotide in the treatment of diarrhoea was $86.7 \%(98 / 113)$, which was significantly higher than the $41.2 \%(46 / 101)$ 


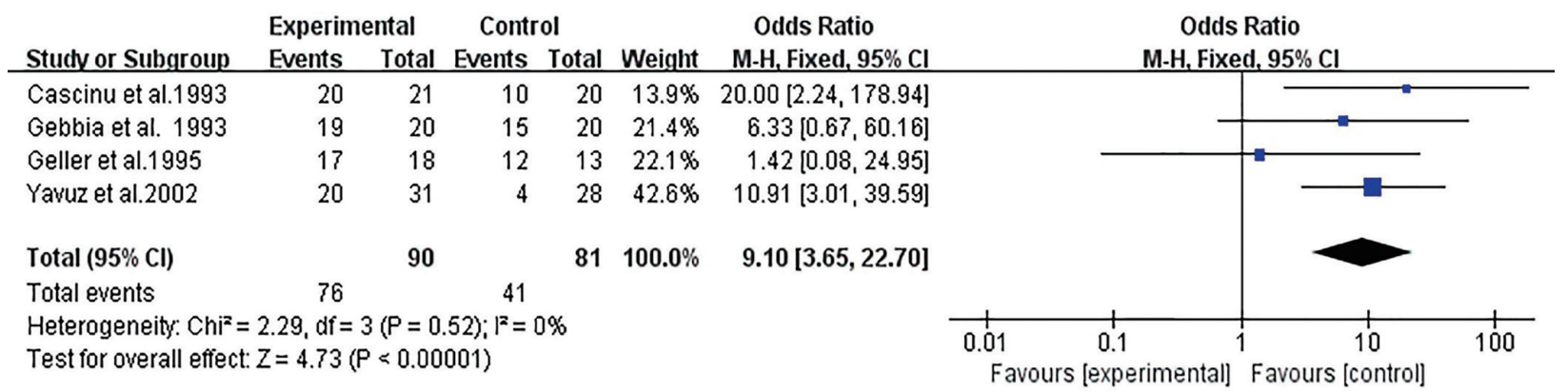

Figure 6 The effective rate comparison of octreotide and opioids in the treatment of chemotherapy- or radiotherapy-induced diarrhoea.

in the control group $(\mathrm{OR}=12.64 ; 95 \% \mathrm{CI}, 5.53-28.90$; $\mathrm{P}<0.00001$ ) (Figure 5).

The effective rate comparison of octreotide and opioids in the treatment of CID or RID

Four studies compared the efficacy of octreotide with opioids in the treatment of chemoradiotherapy-associated diarrhoea. There was no heterogeneity between the studies $\left(\mathrm{P}=0.52, \mathrm{I}^{2}=0 \%\right)$, which were analysed using a fixed-effect model. The results showed that the total effective rate of the study group was $84.4 \%(76 / 90)$, and the total effective rate of the control group was $50.6 \%(41 / 81)$. The difference was statistically significant $(\mathrm{OR}=9.10 ; 95 \% \mathrm{CI}, 3.65-22.70$; $\mathrm{P}<0.00001$ ) (Figure 6).

The effective rate comparison of 24,48 , and $96 \mathrm{~h}$ octreotide group and the control group

Three studies compared the efficacy of chemoradiotherapyassociated diarrhoea in the $24 \mathrm{~h}$ experimental group and the control group. There was low heterogeneity between the studies $\left(\mathrm{P}=0.21, \mathrm{I}^{2}=36 \%\right)$, which were analysed using a fixed-effect model. The results showed that the total effective rate of the study group was $33.3 \%$ (25/75), and the total effective rate of the control group was $7.35 \%(5 / 68)$. The difference was statistically significant ( $\mathrm{OR}=16.02 ; 95 \%$ CI, 3.51-73.15; $\mathrm{P}=0.0003$ ) (Figure 7).

Three studies compared the efficacy of the $48 \mathrm{~h}$ experimental group and the control group in the treatment of chemoradiotherapy-associated diarrhoea. There was no heterogeneity between the studies $\left(\mathrm{P}=0.55, \mathrm{I}^{2}=0 \%\right)$, which were analysed using a fixed-effect model. The results showed that the total effective rate of the study group was $50.0 \%$ $(35 / 70)$, and the total effective rate of the control group was $26.2 \%(16 / 61)$. The difference was statistically significant $(\mathrm{OR}=4.70 ; 95 \% \mathrm{CI}, 1.65-13.42 ; \mathrm{P}=0.004)$ (Figure 7).

Three studies compared the efficacy of the $96 \mathrm{~h}$ experimental group and the control group in the treatment of chemoradiotherapy-associated diarrhoea. There was low heterogeneity between the studies $\left(\mathrm{P}=0.31, \mathrm{I}^{2}=15 \%\right)$, which were analysed using a fixed-effect model. The results showed that the total effective rate of the study group was $76.4 \%$ (55/72), and the total effective rate of the control group was $19.1 \%(13 / 68)$. The difference was statistically significant $(\mathrm{OR}=14.49 ; 95 \% \mathrm{CI}, 6.24-33.65 ; \mathrm{P}<0.00001)$ (Figure 7).

\section{Publication bias}

Due to the limited number of studies having $<10$ cases included, a funnel plot and Egger test could not be used to evaluate the publication bias. Therefore, we performed sensitivity analyses to assess the publication bias. After excluding Cascinu1994 studies, we observed that the publication bias was reduced in this meta-analysis (Table 2).

\section{Discussion}

Our meta-analysis comprehensively and systematically reviewed existing literature. The results showed the following: (I) whether it is chemotherapy or radiotherapy that causes diarrhoea, octreotide is mainly used as a therapeutic drug rather than a preventive drug; (II) octreotide has certain advantages in the treatment of chemoradiotherapy-induced diarrhoea and in terms of effect and treatment time. Compared with general treatment, octreotide can rapidly reduce the clinical severity of diarrhoea caused by radiotherapy and chemotherapy.

To the best of our knowledge, there was a meta-analysis in 2013 to study the use of octreotide as a therapeutic and prophylactic agent in CID (29). Their conclusion was that octreotide has no obvious effect on the prevention of chemoradiotherapy-induced diarrhoea. In contrast, our 


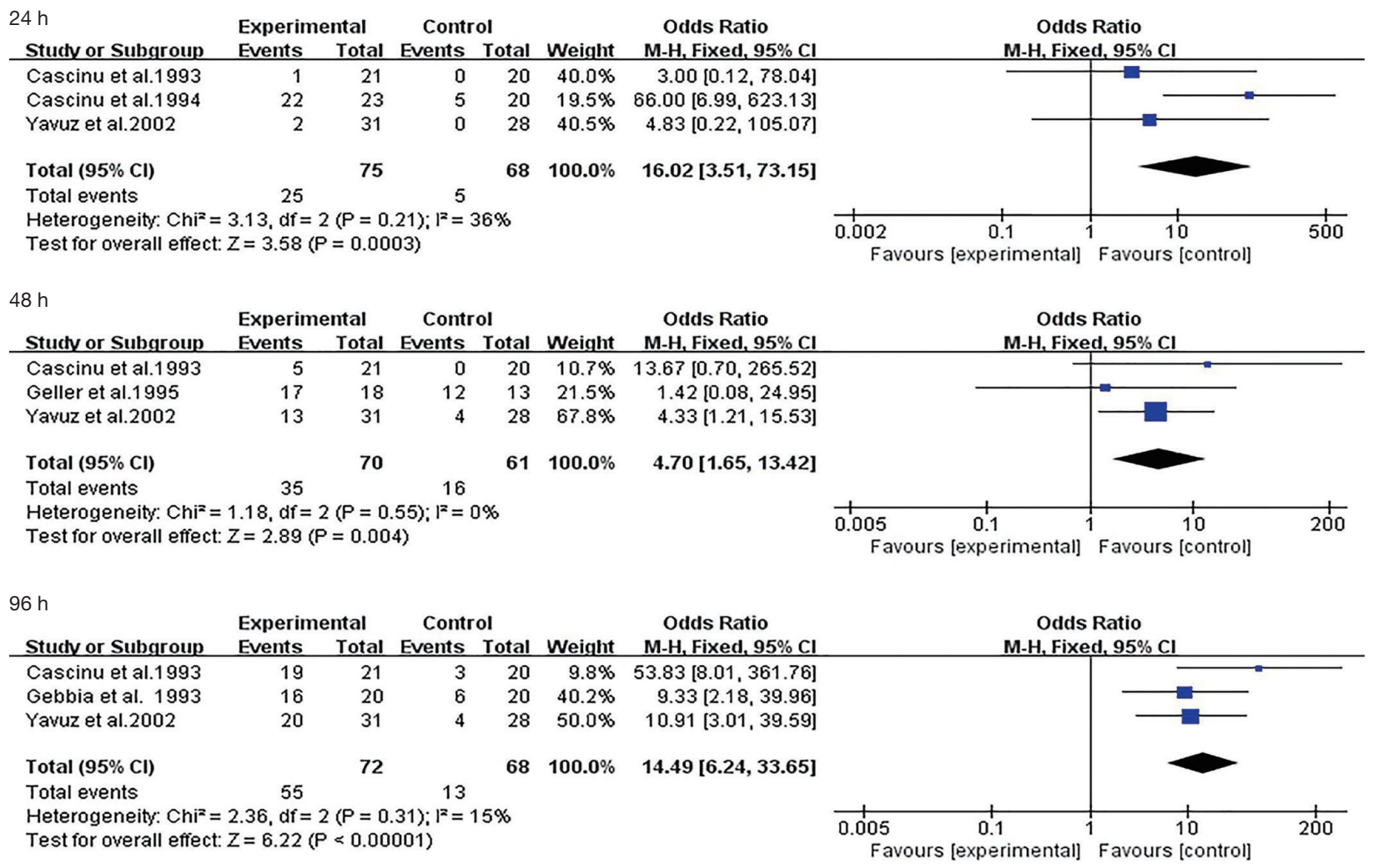

Figure 7 The effective rate comparison of 24, 48, and $96 \mathrm{H}$ octreotide groups and the control group.

Table 2 Publication bias in sensitivity analysis

\begin{tabular}{lccr}
\hline $\begin{array}{l}\text { Meta- } \\
\text { analysis }\end{array}$ & $\begin{array}{c}\text { No. } \\
\text { trials }\end{array}$ & Net change $(95 \%)$ & \multicolumn{1}{c}{$\mathrm{P}\left(\mathrm{I}^{2} \%\right)$} \\
\hline $\mathrm{A}$ & 8 & $3.17(1.28,7.85)$ & $<0.0001(79.0)$ \\
$\mathrm{B}$ & 7 & $2.17(0.98,4.83)$ & $0.001(73.0)$ \\
\hline
\end{tabular}

current meta-analysis includes more recent studies, and we add that octreotide can treat CID more quickly and effectively than general treatment.

The antidiarrheal effect of octreotide may be related to its direct interaction with epithelial cells to reduce the lumen of the upper jejunum and inhibit the secretion of chlorine by stimulating the absorption of sodium and chlorine. Other possible mechanisms include prolonging the oral-caecal transit time (prolonging the contact time between the lumen contents and the mucosal surface), reducing mesenteric blood flow and promoting antiinflammatory effects. Besides, the anti-tumour and antiangiogenic effects of octreotide observed in preclinical studies have suggested the potential to optimize therapeutic indices for chemotherapy and radiation therapy (39).

In the randomized controlled trials included in this study, the study by Geller $e$ t al. included a total of 18 patients that were initially given a subcutaneous injection of octreotide $150 \mu \mathrm{g} / \mathrm{time}$; one patient increased the dose of octreotide during treatment to $300 \mu \mathrm{g} /$ time, 1 patient increased the dose of octreotide to $600 \mu \mathrm{g} /$ time during treatment, 1 patient increased the dose of octreotide to $1,200 \mu \mathrm{g} /$ time during treatment, and finally, diarrhoea reached CR, indicating that increasing the octreotide dose can improve overall efficiency. Increasing the dose of octreotide in some patients may yield better results. Clinically, octreotide is preferred for treatment in patients with symptoms of diarrhoea and opioid therapy failure; for patients with partially refractory diarrhoea, also to increasing the octreotide dose, it may be necessary to use loperamide or opioids in combination, such as comprehensive treatment.

One trial compared octreotide LAR (30 or $40 \mathrm{mg}$ ) at two dose levels to prevent CID in cancer patients with a history of diarrhoea during chemotherapy. A total of 124 patients were evaluated for efficacy in this study. In the 40 $\mathrm{mg}$ group, the number of cases of severe diarrhoea was less 
than that in the $30 \mathrm{mg}$ group $(61.7 \%$ vs. $48.4 \%, \mathrm{P}=0.14)$. Besides, the $40 \mathrm{mg}$ group required intravenous infusion or showed unexpected health effects associated with diarrhoea compared to the $30 \mathrm{mg}$ group. The number of nursing visits was small. However, there was no significant difference between the two groups (40). In another experiment, 12 patients were evaluated. In these 12 patients, $30 \mathrm{mg}$ of octreotide was administered every 28 days from the first day of low-dose chemotherapy. In 10 patients, diarrhoea was significantly reduced while receiving fulldose chemotherapy. This study suggests that the monthly injection of long-acting octreotide can be used as a secondary preventive measure for CID (41). Octreotide in the prevention of radiochemotherapy-induced diarrhoea has not been confirmed to be related to the heterogeneity and sample size of each group during the grouping process. For now, better experimental design and randomized placebocontrolled trials are expected to reveal the true significance of octreotide in radiochemotherapy-induced diarrhoea.

Our meta-analyses extensively assess existing evidence that octreotide can rapidly and effectively reduce the incidence of diarrhoea caused by chemoradiotherapy and improve the quality of life of patients. The patients included in this meta-analysis were patients with malignant tumours receiving chemotherapy or radiotherapy. In a heterogeneous population of all types of malignancies, it is difficult to determine the effectiveness of octreotide for a particular tumour type. Whether octreotide is effective for all kinds of malignant tumours and chemotherapy-related diarrhoea, or is more effective for certain types of tumours, needs further study.

This study also has certain limitations: (I) the quality of the included studies is uneven and the sample size is small, which may cause certain bias; (II) some of the studies did not explain the randomization method, distribution method and statistical analysis methods, which may affect the reliability of the analysis results. In the future, more rigorous multicentre randomized double-blind controlled trials will be conducted to provide more rigorous and objective clinical evidence to further clarify the efficacy of octreotide in the prevention and treatment of chemotherapeutic-associated diarrhoea.

\section{Conclusions}

Octreotide is superior to conventional therapy in the duration and effectiveness for chemoradiotherapyinduced diarrhoea, and octreotide may be considered for the treatment of CID if the patient is in urgent need of improving diarrhoea or is unresponsive to conventional therapy. Octreotide treatment has high efficacy and safety.

\section{Acknowledgments}

Funding: We express our thanks to Grants from Science and technology development plan of Jinan, NO. 201805091; Postdoctoral Science Foundation of China, NO. 2017M612317; National key research and development plan, NO. 2018YFC0114707; Shandong Province key research and development, NO. 2018GSF118047.

\section{Footnote}

Conflicts of Interest: The authors have completed the ICMJE uniform disclosure form (available at http://dx.doi. org/10.21037/tcr.2019.09.49). The authors have no conflicts of interest to declare.

Ethical Statement: The authors are accountable for all aspects of the work in ensuring that questions related to the accuracy or integrity of any part of the work are appropriately investigated and resolved.

Open Access Statement: This is an Open Access article distributed in accordance with the Creative Commons Attribution-NonCommercial-NoDerivs 4.0 International License (CC BY-NC-ND 4.0), which permits the noncommercial replication and distribution of the article with the strict proviso that no changes or edits are made and the original work is properly cited (including links to both the formal publication through the relevant DOI and the license). See: https://creativecommons.org/licenses/by-nc-nd/4.0/.

\section{References}

1. Siegel RL, Miller KD. Cancer statistics, 2019. CA Cancer $\mathrm{J}$ clin 2019;69:7-34.

2. Jung KW, Won YJ, Kong HJ, et al. Cancer Statistics in Korea: Incidence, Mortality, Survival, and Prevalence in 2015. Cancer Res Treat 2018;50:303-16.

3. McQuade RM, Stojanovska V, Abalo R, et al. Chemotherapy-induced constipation and diarrhea: pathophysiology, current and emerging treatments. Front pharmacol 2016;7:414.

4. Bentzen AG, Balteskard L, Wanderas EH, et al. Impaired health-related quality of life after chemoradiotherapy 
for anal cancer: late effects in a national cohort of 128 survivors. Acta Oncol 2013;52:736-44.

5. Mego M, Chovanec J, Vochyanova-Andrezalova I, et al. Prevention of irinotecan induced diarrhea by probiotics: a randomized double blind, placebo controlled pilot study. Complement Ther Med 2015;23:356-62.

6. Shaw C. Treatment-related diarrhea in patients with cancer. Clin J Oncol Nurs 2012;16:413-7.

7. Tarricone R, Abu Koush D, Nyanzi-Wakholi B. A systematic literature review of the economic implications of chemotherapy-induced diarrhea and its impact on quality of life. Crit Rev Oncol Hematol 2016;99:37-48.

8. Shabaruddin FH, Chen LC, Elliott RA. A systematic review of utility values for chemotherapy-related adverse events. Pharmacoeconomics 2013;31:277-88.

9. Kuchuk I, Bouganim N, Beusterien K, et al. Preference weights for chemotherapy side effects from the perspective of women with breast cancer. Breast cancer Res Treat 2013;142:101-7.

10. Cario E. Toll-like receptors in the pathogenesis of chemotherapy-induced gastrointestinal toxicity. Curr Opin support Palliat Care 2016;10:157-64.

11. Demers M, Dagnault A, Desjardins J. A randomized double-blind controlled trial: impact of probiotics on diarrhea in patients treated with pelvic radiation. Clin Nutr 2014;33:761-7.

12. Lau SC, Abdel-Rahman O, Cheung WY. Improved survival with higher doses of octreotide long-acting release in gastroenteropancreatic neuroendocrine tumors. Med Oncol 2018;35:123.

13. Li Y, Wang S, Gao X, et al. Octreotide Alleviates Autophagy by Up-Regulation of MicroRNA-101 in Intestinal Epithelial Cell Line Caco-2. Cell Physiol Biochem 2018;49:1352-63.

14. Colao A, Bronstein MD, Freda P, et al. Pasireotide versus octreotide in acromegaly: a head-to-head superiority study. J Clin Endocrinol Metab 2014;99:791-9.

15. Exner S, Prasad V, Wiedenmann B, et al. Octreotide Does not inhibit Proliferation in Five neuroendocrine Tumor cell lines. Front Endocrinol (Lausanne) 2018;9:146.

16. Bellini C, Cabano R, De Angelis LC, et al. Octreotide for congenital and acquired chylothorax in newborns: $\mathrm{A}$ systematic review. J Paediatr Child Health 2018;54:840-7.

17. Yamamoto R, Shima K R, Igawa H, et al. Impact of preoperative pasireotide therapy on invasive octreotideresistant acromegaly. Endocr J 2018;65:1061-7.

18. Capdevila J, Teule A, Barriuso J, et al. Phase II Study of Everolimus and Octreotide LAR in Patients with
Nonfunctioning Gastrointestinal Neuroendocrine Tumors: The GETNE1003_EVERLAR study. Oncologist 2019;24:38-46.

19. Bellini C, De Angelis L C, Bellini T. Octreotide treatment for neonatal chylothorax. World J Pediatr 2018;14:623.

20. Bajetta E, Catena L, Pusceddu S, et al. Everolimus in Combination with Octreotide Long-Acting Repeatable in a First-Line Setting for Patients with Neuroendocrine Tumors: A 5-Year Update. Neuroendocrinology 2018;106:307-11.

21. Garg PK, Sharma J, Jakhetiya A, et al. The Role of Prophylactic Octreotide Following Pancreaticoduodenectomy to Prevent Postoperative Pancreatic Fistula: A Meta-Analysis of the Randomized Controlled Trials. Surg J (N Y) 2018;4:e182-7.

22. Kruljac I, Vicic I, Blaslov K, et al. The Role of the Acute Octreotide Suppression Test in Detecting Patients with Neuroendocrine Neoplasms. Neuroendocrinology 2018;107:284-91.

23. Hosokawa Y, Kawakita R, Yokoya S, et al. Efficacy and safety of octreotide for the treatment of congenital hyperinsulinism: a prospective, open-label clinical trial and an observational study in Japan using a nationwide registry. Endocr J 2017;64:867-80.

24. Yau H, Kinaan M, Quinn SL, et al. Octreotide longacting repeatable in the treatment of neuroendocrine tumors: patient selection and perspectives. Biologics 2017;11:115-22.

25. Yin R, Zhang R, Wang J, et al. Effects of somatostatin/ octreotide treatment in neonates with congenital chylothorax. Medicine 2017;96:e7594.

26. Borna RM, Jahr JS, Kmiecik S, et al. Pharmacology of octreotide: Clinical implications for anesthesiologists and associated risks. Anesthesiol Clin 2017;35:327-39.

27. Li XN, Rao T, Xu YF, et al. Pharmacokinetic and pharmacodynamic evidence for developing an oral formulation of octreotide against gastric mucosal injury. Acta Pharmacol Sin 2018;39:1373-85.

28. Deng C, Deng B, Jia L, et al. Efficacy of long-acting release octreotide for preventing chemotherapy-induced diarrhoea: protocol for a systematic review. BMJ open 2017;7:e014916.

29. Sun JX, Yang N. Role of octreotide in post chemotherapy and/or radiotherapy diarrhea: prophylaxis or therapy? Asia Pac J Clin Oncol 2014;10:e108-13.

30. Cascinu S, Fedeli A, Fedeli SL, et al. Control of chemotherapy-induced diarrhea with octreotide. Oncology 1994;51:70-3. 
31. Zachariah B, Gwede CK, James J, et al. Octreotide acetate in prevention of chemoradiation-induced diarrhea in anorectal cancer: randomized RTOG trial 0315. J Natl Cancer Inst 2010;102:547-56.

32. Cascinu S, Fedeli A, Fedeli SL, et al. Octreotide versus loperamide in the treatment of fluorouracil-induced diarrhea: a randomized trial. J Clin Oncol 1993;11:148-51.

33. Martenson J A, Halyard M Y, Sloan J A, et al. Phase III, double-blind study of depot octreotide versus placebo in the prevention of acute diarrhea in patients receiving pelvic radiation therapy: results of North Central Cancer Treatment Group N00CA. J Clin Oncol 2008;26:5248-53.

34. Hoff PM, Saragiotto DF, Barrios CH, et al. Randomized phase III trial exploring the use of long-acting release octreotide in the prevention of chemotherapy-induced diarrhea in patients with colorectal cancer: the LARCID trial. J Clin Oncol 2014;32:1006-11.

35. Geller RB, Gilmore CE, Dix SP, et al. Randomized trial of loperamide versus dose escalation of octreotide acetate for chemotherapy-induced diarrhea in bone marrow transplant and leukemia patients. Am J Hematol 1995;50:167-72.

36. Gebbia V, Carreca I, Testa A, et al. Subcutaneous

Cite this article as: Ma DJ, Li ZJ, Wang XY, Zhu XJ, Sun YL. Octreotide treatment of cancer chemoradiotherapyinduced diarrhoea: a meta-analysis of randomized controlled trials. Transl Cancer Res 2019;8(6):2284-2294. doi: 10.21037/ tcr.2019.09.49 octreotide versus oral loperamide in the treatment of diarrhea following chemotherapy. Anticancer Drugs 1993;4:443-5.

37. Yavuz MN, Yavuz AA, Aydin F, et al. The efficacy of octreotide in the therapy of acute radiation-induced diarrhea: a randomized controlled study. Int J Radiat Oncol Biol Phys 2002;54:195-202.

38. Kicinski M, Springate DA, Kontopantelis E. Publication bias in meta-analyses from the Cochrane Database of Systematic Reviews. Stat Med 2015;34:2781-93.

39. Martelli L, Colard A, Fontaine F, et al. Evaluation of the efficacy of octreotide LAR in the treatment of Crohn's disease associated refractory diarrhea. Scand J Gastroenterol 2017;52:564-9.

40. Rosenoff SH, Gabrail NY, Conklin R, et al. A multicenter, randomized trial of long-acting octreotide for the optimum prevention of chemotherapy-induced diarrhea: results of the STOP trial. J Support Oncol 2006;4:289-94.

41. VAN DEN Heuvel B, Peeters M, Hendlisz A, et al. Long-acting octreotide as secondary prevention of chemotherapy-induced diarrhea: proof of concept. Minerva Chir 2016;51:231-4. 